\title{
SELECTED ISSUES IN UNIVERSAL DESIGN OF YACHTS FOR PEOPLE WITH DISABILITIES
}

\author{
Bogdan Branowski \\ Marek Zabłocki* \\ Przemysław Kurczewski \\ Andrzej Walczak \\ Poznan University of Technology, Poland
}

*Corresponding author: marek.zablocki@put.poznan.pl (M. Zabłocki)

\begin{abstract}
This paper presents the general principles of building a sailing yacht designed for people with multiple disabilities. Specific requirements for the crew on such vessels have been stressed. A lot of attention has been given to the possible disabilities of the design subjects and accessibility of the new yacht. The universal design method has been adopted to enable meeting ergonomic and rehabilitation requirements. We discuss selected stages of the design process: problem analysis, yacht construction and equipment. We discuss the influence of the type of disability on yacht use, in detail. Two tasks have been combined, that of a sailor with disabilities and that of a yacht. Both of them need to be taken into account in the socio-technical 'sailor with disabilities - yacht' system. A set of required yacht adaptations has been developed to meet the relationships in this system. Typical dangers in sailing on the Empatia 60 FD yacht are further enumerated. We provide a set of design rules for constructing dedicated yachts for the disabled and their practical use.
\end{abstract}

Keywords: sea yacht for disabled persons, universal design, human factors

\section{SUBJECT AND PURPOSE OF YACHT DESIGN}

Full accessibility of living space is the basis of everybody's independent acquisition of experience and knowledge. Yachting enables people with disabilities and seniors to explore the world, interact with other people, and make their individual plans and ambitions come true. A training and recreational yacht is designed for the active acquisition of knowledge and sailing experience, as well as for active recreation and rehabilitation of the disabled or seniors. It is assumed that the yacht's crew will be made up of people with various motor, sensory, mental and age-related disabilities. On a yacht, such disabilities make it difficult to:

- walk, stand, and, sometimes, sit for people with damage to lower limbs, spine and neurological, cardiac, renal ailments,
- grasp and hold, in the case of upper limb injuries,

- get oriented in space, in the case of visual impairment,

- receive auditory information, when hearing is impaired.

In addition, these people change from voyage to voyage. This, in turn, results in a change in the structure of disabilities and creates difficulties in assembling watch crew. This is because it is assumed that the yacht could be fully operated by a crew dominated by people with disabilities. What matters is the high ratio of disabled sailors to professional yacht crew of 3:1 to $4: 1$, with a total crew of 15 to 16 crew members. This is a completely new concept in the construction of a Category A yacht. The new yacht can also perform recreational, active leisure functions on short voyages along the coast.

To recapitulate, there are several purposes for building a yacht for people with disabilities:

- running integration and therapeutic classes and cruises (e.g. disabled people in wheelchairs with their caregivers), 
- conducting training in sailing ranks,

- participation in regattas, races and rallies of sailing ships with disabled crews for international integration,

- rehabilitation on yachts for the improvement of physical, mental and social health in people with disabilities and giving them the opportunity to live a normal life with equal rights and, possibly, equal responsibilities as nondisabled persons,

- opening of the domestic market of active sailing tourism for people with various physical disabilities, which requires permanent yacht adaptation.

A yacht realising these objectives needs to be highly innovative. Sailing and rigging should enable disabled persons to operate the yacht on their own without the help of nondisabled persons. The crew and watch make-up must be skilfully selected from among sailors with different types of disabilities, to form a team efficient in operating the yacht. The safety system must ensure the possibility of self-evacuation with life-saving systems and monitoring of the crew's health condition, such as smart-bands, reading the yacht location and signalling of hazards (fall, falling overboard). Two control stations have been planned for crew training. Kitchen accessibility for seniors, the disabled on wheelchairs and the visually impaired will be guaranteed by the use of lowering cabinet interiors and/or lifted tabletops. A similar, compact solution for sanitary facilities would enable selfservice in the bathroom and WC. Due to space constraints and specific conditions, the yacht will be equipped with a specialised yachting wheelchair. The planned inter-deck start-lifts are intended to ensure accessibility of the lower deck and evacuation of wheelchair users in the absence of electrical power during a water or fire alarm. The modern design will also be a distinctive feature. Due to crew disability, especially the presence of wheelchair users, the dimensional proportions of the yacht's hull need to be changed. The yacht (Fig. 1) with a deck length of $18 \mathrm{~m}$ (60 ft) is relatively wide $(6 \mathrm{~m}, 20 \mathrm{ft})$, which is to ensure accessibility of the deck and the interior of the superstructure for wheelchair users (Table 1).
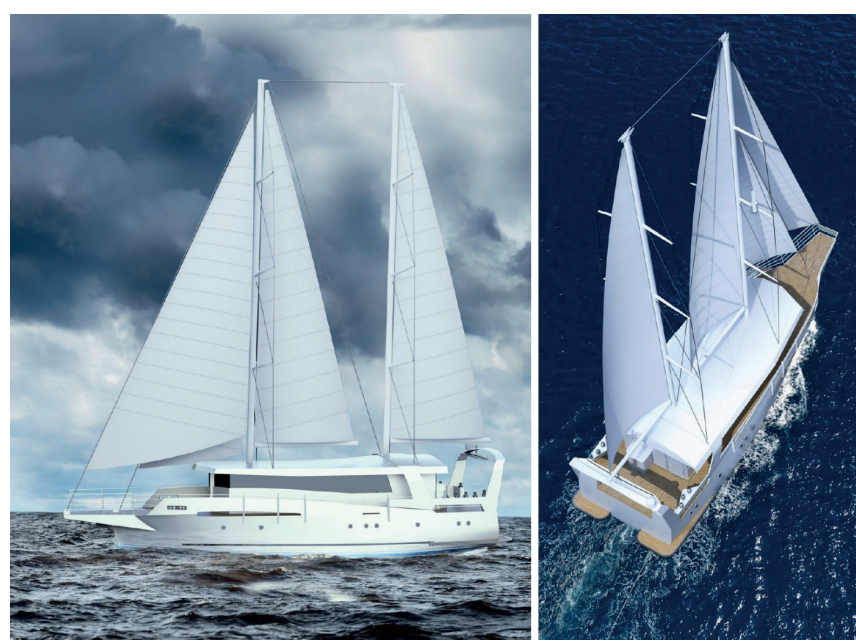

Fig. 1. The designed yacht for disabled users
Tab. 1. Technical parameters of the designed yacht for the disabled

\begin{tabular}{|l|c|}
\hline \multicolumn{1}{|c|}{ Tentative name } & $\begin{array}{c}\text { Empatia 60 FD } \\
\text { (For Disabled) }\end{array}$ \\
\hline Place of construction & Polska \\
\hline Length $\times$ width [m] & $17,99 \times 6,05$ \\
\hline $\begin{array}{l}\text { Number of persons/number of disabled } \\
\text { persons }\end{array}$ & $\begin{array}{c}-16 / 12 \text {, including up to } \\
\text { 4 persons on wheelchairs }\end{array}$ \\
\hline Number of sails [pcs.] & 5 \\
\hline Number of masts [pcs.] & 2 \\
\hline Displacement [t] & 2,80 \\
\hline Draught [m] & $190-290$ \\
\hline Sail area [m $\left.{ }^{2}\right]$ & $\begin{array}{c}2 \text { internal combustion } \\
\text { engines, } 88.26 \mathrm{~kW} \text { each }\end{array}$ \\
\hline Propulsion $[\mathrm{kW}]$ &
\end{tabular}

Specialised yachts dedicated to people with disabilities are rarely encountered anywhere in the world. For example, three such vessels are known in Europe: Wappen von Ueckermünde, URI and Empatia. The parameters of these yachts are given in Table 2.

Tab. 2. Known yacht structures dedicated to people with disabilities

\begin{tabular}{|l|c|c|c|}
\hline \multicolumn{1}{|c|}{ Yacht name } & $\begin{array}{c}\text { Wappen von } \\
\text { Ueckermünde }\end{array}$ & URI & Empatia \\
\hline Place of construction & Germany & Netherlands & Poland \\
\hline Length x width [m] & $21,98 \times 5,6$ & $16,43 \times 5,6$ & $13,4(14,2) \times 3,95$ \\
\hline $\begin{array}{l}\text { Number of crew } \\
\text { members/number } \\
\text { of disabled persons }\end{array}$ & $\begin{array}{c}-10 / 4 \text { in } \\
\text { wheelchairs }\end{array}$ & $\begin{array}{c}-6 \text { - yacht for } \\
\text { persons in } \\
\text { wheelchairs }\end{array}$ & -7 (berths) \\
\hline $\begin{array}{l}\text { Number of sails } \\
\text { [pcs.] }\end{array}$ & $5+2$ & 3 & 3 \\
\hline $\begin{array}{l}\text { Number of masts } \\
\text { [pcs.] }\end{array}$ & 2 & 1 & 2 \\
\hline Displacement [t] & 45 & 38 & 18 \\
\hline Draught [m] & 2,3 & 2,4 & 2,15 \\
\hline Sail area [m $\left.{ }^{2}\right]$ & 235 & 128,5 & 110 \\
\hline Propulsion [kW] & 84 & 111 & 47,8 \\
\hline
\end{tabular}

A previously known, large vessel adapted for disabled persons was the training sailing vessel STS Lord Nelson, with a length of approximately $55 \mathrm{~m}$ [1]. This sailing ship was, therefore, different in size from the other abovementioned vessels. On the sailing ship, half of the crew, usually up to 20 people, could be people with disabilities. It was decommissioned in 2019.

\section{SUBJECT OF DESIGN - USERS WITH DISABILITIES AND SENIORS}

Disability impairs functional, especially somatic, ability and life activity to the extent that it impedes the performance of social roles. It is estimated that over a billion people (about $15 \%$ of the world population) live with some form of disability $[2,3]$.

For example, people with motor disabilities constitute almost half of all the disabled in Poland [2]. Such a disability also includes a reduction in the manipulative movements of the upper limbs, the locomotor movements of the lower limbs and often results in the need to use a wheelchair. Mobility 
disabilities are not only about using a wheelchair, but also dysfunctions of the skeletal, articular, muscular, vascular and nervous systems. The extent and severity of these disabilities can be exacerbated in a yachting environment with a sloping or wobbling deck, in a confined space with architectural and communication barriers, and difficult environmental conditions caused by wind and sea swell.

There are many human factors in the design. The yacht needs to be accessible, safe and friendly to seniors and people with disabilities. Accessibility provides for a possibility of using the yacht's functions despite existing barriers and performing the intended service. Barriers on a yacht are due to uneven and slippery surfaces, obstacles in traffic routes, high kerbs, thresholds, stairs and steps, narrow doors and entrances, poor lighting, lack of visual and audible information and traffic lights. Correct design of traffic routes, construction and friendly onboard equipment greatly facilitates moving around on a yacht. It is a matter of adapting the tangible living and working environment and the surrounding objects to the ergonomic physical and mental limitations of human faculties. Adapting the yacht to mobility constraints includes reaching, grasping, holding, wheelchair manoeuvring, walking and overcoming height differences in the yacht space, as well as mobility possibilities. For example, physical accessibility can be improved by graspability with right or left hand only, minimising the need for precision movement, possibilities for alternative handling or operation, no sense of stigmatisation or segmentation when using the technical solution, visibility from any position, access to all privacy functions regardless of possible errors and risks, and user comfort.

\section{DESIGN METHOD}

Universal Design was chosen as a method focused on the needs of seniors and people with disabilities, more specifically social engineering design for all, regardless of age or disability. There are dozens of similar design types. The work by M. Zablocki [3] identifies 30 terms for similar design varieties, ensuring the accessibility of products, buildings or environment for all people without the need for adaptation or specialised treatment. The 'Universal Design' term is very much in line with closely related terms such as Inclusive Design, Design for All, and Assistive Technology. The design concepts, different in name but similar in content, are linked by the focus on the user with different psychophysical abilities. Universal design is one of the many methods used in technology. In yacht design, the method of the so-called Evan's ship design spiral (Evans) from the concept to the concrete solution with a record of subsequent activity iterations has become popular $[4,5]$. This method may be applied to the design of yacht hulls [6].

The correct shaping of the spatial structure of a yacht consists in adapting the yacht to the ergonomics and rehabilitationrelated needs of people with disabilities, especially those with motor skill limitations like wheelchair users. The specific character of work stages for the yacht under consideration was taken into account in the design process. The first stage included the analysis of the required geometrical, kinematic, force and energy issues for the specified spatial structure of the yacht. At the construction stage, special attention should be paid to equipping the yacht with new devices (e.g. lifts, wheelchairs) supporting mobility and accessibility to the upper and lower decks, control room, control and navigation devices, camboose and mess room, berths, WC, lifts and navigation table. Special yachting equipment includes rails, pipes, cleats and capstans for rigging and sails, with furlers adapted for disabled people. Similarly, the yacht design should also cover colours, surface textures and lighting of the yacht's working and resting areas, especially for the visually impaired. The choice of geometry and materials for people with grasping and manipulation problems, such as rheumatoid arthritis, or people with tetraplegia, is also important.

\section{THE INFLUENCE OF THE TYPE OF DISABILITY ON YACHT USE}

The yacht's crew consists of a professional team of permanent users (skipper, boatswain, cook) and periodic users who change from voyage to voyage: mainly sailors with disabilities, their care-givers, volunteers and instructors. In these groups, people with disabilities are of particular interest.

There are many types of disabilities, each of which presents a challenge to sailing because of the need for different adaptations of technical equipment.

People with limited mobility (spinal cord injuries, cerebral palsy, paralysis, paraplegia or tetraplegia, muscular dystrophy, cystic fibrosis, amputations, multiple sclerosis and arthritis) tend to get easily tired due to muscle weakness and spasticity. Mobility may increase susceptibility to hypothermia in cooler weather conditions or hyperthermia in hot and humid environments. Difficulties with balance and coordination of movement may occur with serious core injuries and sensory loss. Reduced sensitivity to foot and leg injuries occurs in patients with limb paralysis. This requires the use of soft footwear (e.g. trainers), the removal of sharp edges on the boat and the absence of salt deposits on the surfaces under the buttocks of a person with spinal cord injury (SCI). Loss of bladder and bowel control involves another set of problems. People with such disabilities may use mobilityenhancing equipment (wheelchairs, walkers, crutches) which, however, entail difficulties in moving up and down stairs, for example. Sitting or standing for long periods can entail further problems. Some of the medicines used affect stamina.

People with developmental disabilities (Down syndrome, traumatic brain injury, cerebral palsy, autism, cystic fibrosis, muscular dystrophy and epilepsy) tire easily, need modifications to the vessels and increased assistance from instructors and volunteers. They exhibit a reduced ability to feel pain and injury. Diabetics need to monitor their sugar levels, maintain a suitable diet and have insulin available for the duration of the voyage. 
Visually impaired people (for example, those suffering from congenital blindness, nodules, strabismus, cataracts, diabetic retinopathy, glaucoma, macular degeneration) have difficulties in orienting themselves on the yacht, in determining the direction of water movement, the location of the yacht and equipment, and in sensing direction and distance from other vessels, buoys on the water, understanding wind direction and speed. Sound assistance and touch guidance on the yacht are needed.

People with hearing impairments (hearing loss or impairment, neuropathy) need labelling on equipment, visualisation of signs and well-defined and consistent signalling.

People with cognitive impairments (autism, dementia, attention deficit disorder, dyslexia, aphasia and learning difficulties) show difficulty in understanding safety levels under sudden changes in direction of the boat and heels. Their lack of fear can be positively affected by gentle encouragement and sailing training.

Therefore, disability limits the performance of functions on a yacht. Table 1 presents examples of activity ranges for people with and without disabilities.

Tab. 3. Examples of activity ranges for people with and without disabilities

\begin{tabular}{|c|c|c|}
\hline Activities & $\begin{array}{l}\text { Able- } \\
\text { bodied } \\
\text { people }\end{array}$ & $\begin{array}{l}\text { Persons with disabilities - the } \\
\text { range of options is determined by } \\
\text { the type of disabilit }\end{array}$ \\
\hline $\begin{array}{l}\text { Moving around the } \\
\text { yach }\end{array}$ & full range & restricted range \\
\hline $\begin{array}{l}\text { Yacht-shore } \\
\text { communication }\end{array}$ & full range & restricted range \\
\hline Navigation & full range & full range \\
\hline Logbook entries & full range & full range except for blind people \\
\hline $\begin{array}{l}\text { Operation of the } \\
\text { VHF radio }\end{array}$ & full range & $\begin{array}{l}\text { full range except for deaf-mute } \\
\text { people provided the radio is } \\
\text { assembled in an accessible location }\end{array}$ \\
\hline Controlling & full range & full range with 'talking compass' \\
\hline Engine work & full range & full range \\
\hline Observing & full range & restricted range \\
\hline $\begin{array}{l}\text { Work with sails and } \\
\text { lines }\end{array}$ & full range & $\begin{array}{l}\text { limited range dependent on how } \\
\text { the ropes are brought into the } \\
\text { cockpit }\end{array}$ \\
\hline Manoeuvres & full range & restricted range \\
\hline $\begin{array}{l}\text { Working in the } \\
\text { camboose }\end{array}$ & full range & restricted range \\
\hline $\begin{array}{l}\text { Indoor work - e.g. } \\
\text { cleaning }\end{array}$ & full range & restricted range \\
\hline Yacht maintenance & full range & $\begin{array}{l}\text { limited range - without the ability } \\
\text { to climb the mast but in some } \\
\text { places can, e.g. remove rust or } \\
\text { replace the rope }\end{array}$ \\
\hline $\begin{array}{l}\text { Self-service on the } \\
\text { yacht }\end{array}$ & full range & restricted range \\
\hline
\end{tabular}

It follows that only a small number of important yacht handling activities can be carried out without restrictions by people with disabilities. Such activities may include navigation or control, but the performance of these functions requires the use of specialised assistive technology solutions, e.g. 'talking compass and navigation aids'.

\section{THE 'DISABLED YACHTSMAN' SOCIOTECHNICAL SYSTEM AND THE DESIGN PROCESS}

The yacht design process is iterative, with gradually increasing identification of design features. It follows a kind of hierarchy of proceedings and can be computer-modelled in many variants [4]. It is assumed that the design process follows the principles of universal design of the 'sailor - yacht' system and connects the structure of the two related streams: recognition and analysis of human activities on the yacht and analysis of the yacht accessibility for the execution of technological yacht tasks (Fig. 2).

The two identified trends integrate the concept of universal design for all, regardless of age, gender or disability. The huge diversity of people on a particular voyage, changing from voyage to voyage, makes this design particularly difficult. This diversity relates to human physiological, psychological, anthropometric or cultural characteristics and has an impact on the possible parameters related to disabilities, working posture, handling space, loads, rhythm and work methods. These features of yacht users limit the usability of the previously used technological measure and create new functional needs of these technical devices to perform the tasks acceptably. The specific devices for yacht operation and accessibility measures must be structured and correspond to the environmental conditions and parameters of the work process. The feedback between people with disabilities or seniors and technical measures, the products of universal design and their functional, spatial and temporal transformations in the process of use form sociotechnical systems.

Applying Ropohl's [7] philosophy of socio-technical systems, introduced into Polish literature by M. Gawrysiak [8], it should be noted that a human being is a system itself, within the 'human-yacht' super-system. According to Ropohl, the action system, i.e. transformation of inputs, states and goals of the system into information, energy and mass outputs, is the basic system of technical object creation and use. The human system interacts with action systems. Additionally, there is a division of labour into a chain of functionally coordinated activities and actions. Most often, this very integration forms the sociotechnical system. Sociotechnical integration takes the form of substitution (of human activities, e.g. movement, forming) and the form of complementation (substitution of human functions by the functions of a technical device for the general purpose of relieving a human being, for example, by using a wheelchair, a navigation chair with a horizontal stabilisation system).

The human-technical device relations relate to somatic functions, receptors and psychophysical integrity. These relations are at the core of ergonomic design. As presented in Fig. 2, task analyses (manual or assisted work), allocation analyses (risk, geometric accessibility analyses) and analyses of the fulfilment of physical-psychological requirements (strength, posture, execution of movements) are performed during the design. 


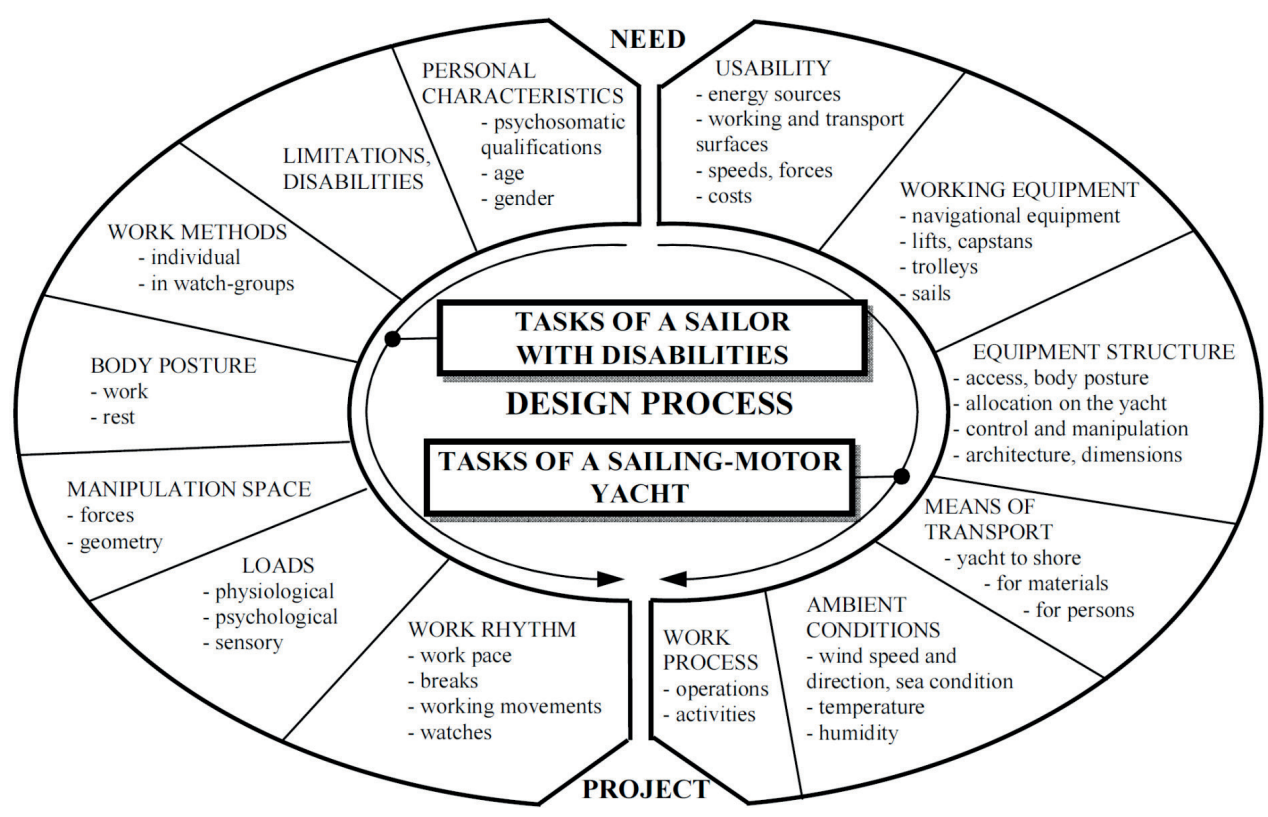

Fig. 2. Structure of the design process for the 'person with a disability - sailing-motor yacht' system

To achieve socio-technical integration of people with disabilities and seniors in the designed yacht, we propose to apply the adaptations given in Table 4 . This set of ergonomic requirements will be the basis for proposing specific structural solutions and yacht equipment.

Tab. 4. Planned adaptations of the yacht under design

\begin{tabular}{|c|c|}
\hline Disabilities & Adaptations \\
\hline motor disabilities & $\begin{array}{l}\text { small angle of deck inclination (for crew balance, } \\
\text { wheelchair traffic), deck with non-slip lining (for } \\
\text { crutches), handrails under the deck, rails around } \\
\text { the deck, steering wheel rails, baskets at masts, } \\
\text { handholds adapted for grip defects, bridges, boarding } \\
\text { ramps, yacht layout arrangement, high boom, easy } \\
\text { sail handling (rope markings, special structures for } \\
\text { steering in a seated position), audible navigation, free } \\
\text { passages along the yacht, inter-deck lift, WC, shower } \\
\text { for wheelchair users, kitchen furniture adapted for } \\
\text { wheelchair users and anthropometry of the crew, } \\
\text { liftable massage table - equipment for individual } \\
\text { rehabilitation }\end{array}$ \\
\hline $\begin{array}{l}\text { intellectual } \\
\text { disabilities }\end{array}$ & $\begin{array}{l}\text { small deck inclination angle (for crew balance and } \\
\text { wheelchair traffic), handrails, rails around the deck, } \\
\text { steering wheel rails, boarding bridges, yacht layout, } \\
\text { high boom, sail handling facilities (rope colour } \\
\text { coding, special constructions for steering in seated } \\
\text { position), audible navigation, free passages along } \\
\text { the yacht }\end{array}$ \\
\hline sense of sight & $\begin{array}{l}\text { navigation with sound compasses and voice- } \\
\text { controlled rudders, high boom, colour scheme } \\
\text { adapted to the visual impairments, navigation maps } \\
\text { with convex shapes and Braille information, stickers } \\
\text { with voice information }\end{array}$ \\
\hline hearing sense & $\begin{array}{l}\text { yacht electro-inductive loop system, smartband-type } \\
\text { location of persons on the yacht with the signalling } \\
\text { of risk of falling or falling overboard, light, vibration } \\
\text { signalling at berths }\end{array}$ \\
\hline $\begin{array}{l}\text { secondary (e.g. } \\
\text { diabetes, asthma) }\end{array}$ & $\begin{array}{l}\text { space for monitoring equipment for patients, drugs } \\
\text { for diabetes and other diseases }\end{array}$ \\
\hline
\end{tabular}

\section{DESIGN PRINCIPLES}

\section{INTRODUCTION}

Technical design principles influence design decisions. They are very often a result of practical actions. The knowledge of these principles is not a guarantee of effective design as there are always cases that escape any rules. Principles are kinds of scientific laws that subordinate the effectiveness of the design object with regard to the selection of actions and structural features. These technical principles of methodological machine design schools, both Polish (J. Dietrych [9]) and or German (G. Pahl and W. Beitz [10]), lack contexts related to the user of the anthropotechnical system.

The so-called systemic principles of universal design, known from the literature, focus on the unambiguous representation of relations in the sociotechnical system. They constitute a set of seven postulates that are difficult to apply in practice. When designing a yacht for disabled persons, they take precedence over the other principles of design, discussed at a later stage.

The design principles for constructing technical means for the disabled, presented in Table 5, regulate practical activities in the design process in the sense of 'this is how it should be!' with no guarantee of efficiency. They include operation basics (technical functions) and the essential features of the design solution.

Technical solution principles define the basis from which solutions for design tasks are derived, including principles of operation and essential structural features. The principles of operation are the basis for the realisation of technical functions (physical effects and integration of individual functions). 
In design, construction principles are, in addition to criteria, the logical basis for the identification of structural features (geometric, material and dynamic).

\section{DESIGN PRINCIPLES OF YACHT ENGINEERING DEVICES FOR THE DISABLED AND SENIORS}

The principles of yacht design for the disabled (Table 5) are used to evaluate and select functions and conceptual solutions, as well as shape structural features of the technical device, i.e. the yacht and its equipment (interdeck lifts, bathing platform, steering position etc.). The presented set of construction principles has been developed based on our reflections and creative conclusions from methodological discussions with skippers and disabled sailors, as well as analysis, modification and reformulation of known principles of mechanical constructions, principles of ergonomics and principles of the rehabilitation process.

\section{Tab. 5. General and derivative principles for the construction of technical measures in design for the disabled}

1. Principle of an optimal division of functions between the human person and the technical measure: 1.1. Division of tasks between the disabled sailor and the technical device e.g. electric furlers and winches, rudder seat with verticalisation options; 1.2. Integration of partial device functions e.g. stern platform for bathing and disembarking; 1.3. Function 'freezing' ('disappearing device' that still stay within reach) e.g. wheelchair which takes little space at berth when folded; 1.4. Absolute preservation of basic safety functions e.g. electric lift drive and independent manual drive during evacuation and power failure

2. Optimum load principle: 2.1. Optimal physical and psychological load on the human body in the use process e.g. rudder forces matched to disabilities and loads; 2.2. Optimal flow of forces through the device e.g. articulated or spring support of wheelchair wheels, prevention of overloads, selection of material and economic profile for each type of component load; 2.3. Intended instability, e.g. using an active wheelchair in a balance or a Segway-type self-balancing two-wheeler; 2.4. Uniform load distribution e.g. pneumatic decubitus cushion for the helmsman; 2.5. Forced influence e.g. foot protection on the wheelchair against impacts of yacht elements, removal of sharp-edged elements from the deck

3. The self-supporting technical mean principle: 3.1. Safe design e.g. elastically or plastically deformable zones for foot guards in case of collision of the wheelchair with the yacht sides, use of vibration dampers, wheelchair cushions; 3.2. Self-reinforcement e.g. using the inertia of the rotating parts of the wheel ring to compensate for unevenness of movement and increase the steerability of the wheelchair and the rudder; 3.3. Complementing human functions without useless or harmful redundancy e.g. self-service in WC and bathroom; 3.4. Intrinsic safety, e.g. shape and spacing of capstan parts to prevent crushing or cutting body parts

4. Structure ordering and fit principle: 4.1. Minimisation of errors e.g. control of two wheelchair parking brakes from one place; 4.2. Device invariance e.g. single brake adjustment with non-linear wear compensation spring; 4.3 . The adaptability of the technical device to the anthropometric dimensions, body position and amplitude of movement on the yacht, physical abilities and individual preferences e.g. lifting worktops, toilet; 4.4. Optimal adaptation of the device structure to changing anthropometric and psychophysical features of a human, e.g. a seat adapting to the deflections of a yacht; 4.5. Avoidance of sharp edges, protruding and moving parts of mechanical devices in manual activity areas e.g. lift and bathing platform drive elements; 4.6. Optimal use of material [11] e.g. repairable, recyclable materials, limiting the number of different materials and/or their combinations; 4.7. Use of a functional material in a functionally important place e.g. human-device interaction surfaces
5. Collision overcoming principle: 5.1 . The collision between system safety and simple device design preserving the relationship of lightweight and robust design without sacrificing safety and cost; between the reliability of parts/components and functions and protection of people from accidents and hazards at a given risk level in the execution of intended and unintended actions and environmental safety; 5.2. The collision between utility and economic characteristics, e.g. reliability and durability versus price

6. Principle of optimal use of energy; 6.1. Human energy, e.g. when using a drive or control device with intrinsically inherently limited use of human energy, ensuring maximum efficiency of human-device energy conversion, taking into account climate conditions and body chilling: wind, rain on board; 6.2. Device energy e.g. reduction of irreversibility or energy recuperation with an alternative or hybrid muscle-electric drives; 6.3. The principle of minimising the harmful effects of various energy types, i.e. protecting humans and the environment from harmful mechanical, acoustic, hydraulic, pneumatic, electrical, optical, thermal, chemical effects

7. User-friendliness principle: 7.1. Optimal mobility e.g. in wheelchairs: lightness, manoeuvrability and low movement resistance, overturning prevention, intelligent mechatronic wheelchair and stationary rudder seat control; 7.2. Optimal support, e.g. anti-decubitus seats with even load distribution and ventilation: an anatomical seat, active shell seat, cushion with foam or gel filling; adjustable backrest with optional relaxation position; vibration damping and spinal relief with spring-elastomer cushioning of the wheelchair frame; 7.3. Integral possibilities of all-day support with rehabilitation measures and aids for various work, therapy, leisure and self-care activities on the yacht; 7.4. Individual adaptation through multi-variants, e.g. modules attachable to the product platform, component series and families for wheelchair reconfiguration for different work and leisure environments; intuitive adjustment of the support zones and the settings for optimum adaptation of the technical means to the person; 7.5. Comfort with different standards, quality e.g. functional system integration with freedom of changes in aesthetic choices: combinations of materials and equipment elements, their style, colours and design

\section{CASE STUDIES ON THE APPLICATION OF DESIGN PRINCIPLES}

The construction principles given, enable solving problems connected with the integration of the specific 'disabled sailor - yacht' socio-technical system.

The positioning and operation relations between the elements of the 'disabled person-wheelchair-yacht' system must be mutually adapted. For example, manipulation of the classical rudder might be impossible for a person in a wheelchair due to the limited manipulation space of the helmsman, whose legs do not allow a closer approach to the steering stand (Fig. 3a). Besides, this solution does not take into account the possible grip deficiencies of a tetraplegic. The design of a rudder allowing the wheelchair to approach and manipulate it constitutes the application of rules 1 and 4 (Figure 3b) [12]. Part of the steering wheel is placed below the deck to provide a dedicated area for stable wheelchair positioning. The solution known from Fig. 3c, allows for approaching and manipulating the rudder (steering wheel) by a tetraplegic with various grip defects because of special grips adapted to such a disability. A set of such grips is presented in Fig. 3d. 


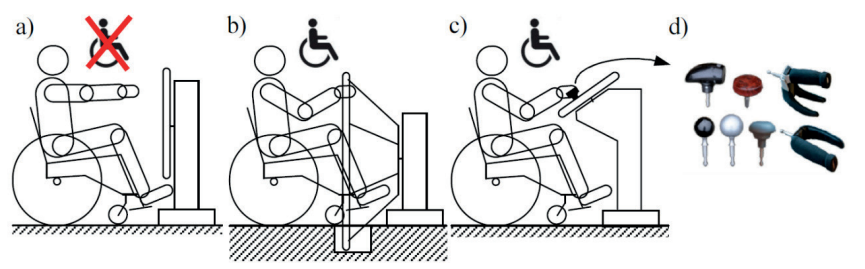

Fig. 3. Configurations of the wheelchair user - rudder system: a) unadapted due to inability to grasp the rudder, $b$ ) adapted with special rudder geometry, c) adapted to a disabled person with impaired grip, d) special DTS2 grips attached to the rudder for different user disability degrees

A yacht for the disabled can be controlled from two independent stands by a skipper or a disabled sailor (e.g. in a wheelchair). Implementation of rules no 1, 1.1, 2.3 and 4.3 requires that the sitting on a chair changing its position depending on yacht inclination, provides safety for a person with an unstable torso. Seat tilt can be compensated by using a mechatronic drive of the gyroscopically controlled seat support lever (Fig. 4).

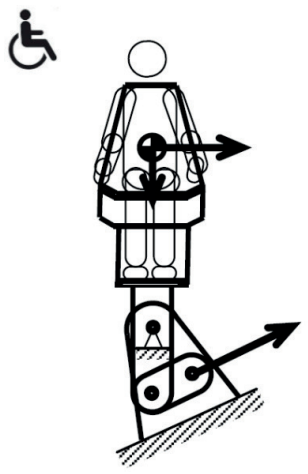

Fig. 4. Mechatronic tiltable seat controlled with a gyroscopic device adjusting the steering seat to the yacht's inclination (drawing based on [13])

Inter-deck transport of a person in a wheelchair poses serious problems on a yacht. Difficulties arise from safety requirements in emergencies with the electric drive switched off. In such cases, the lift must be equipped with an independent manual drive. Yacht transport lifts are usually made for disabled sailors (Fig. $5 \mathrm{~b}$ and $5 \mathrm{c}$ ). The application of principles no $3,4.3,4.4$ and 7.2 to yacht design requires the use of two platform lifts with unilaterally fixed guides, the so-called stair-lift (Fig. 5a).

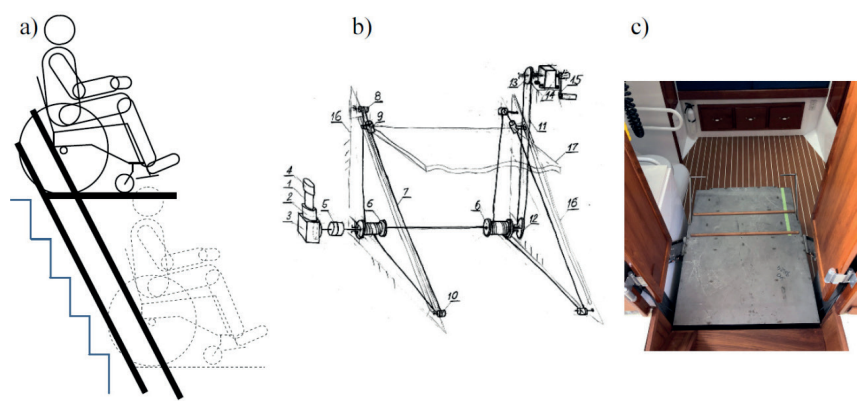

Fig. 5. Yacht lifts: a) platform lift with unilaterally fixed guides, b) platform lift with bilaterally-fixed guides with electric drive and emergency manual drive, c) view of the lift [14] on the Obsession yacht
There are difficulties in the working space on the yacht resulting from a maladaptation of the manipulation space to wheelchair users. It is possible to make accessible space in each of the three workstations through a lifting work object (e.g. a cabinet) (Fig. 6a), 'extending' the upper limbs (e.g. a manipulator with a grip) (Fig. 6b) or raising the wheelchair seat (Fig. 6c). These solutions evade principles 1.1, $1.2,4.3$ and 4.4 .

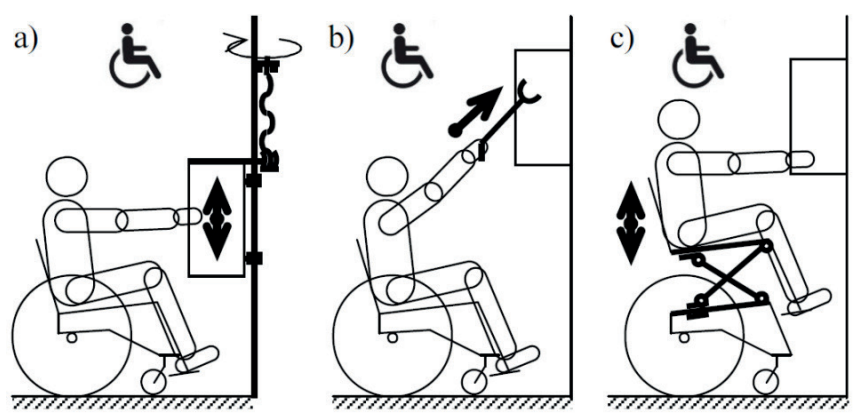

Fig. 6. Possibilities of adapting the required manipulation space to the hand reach of wheelchair users: a) by changing the position of objects in the environment, b) by extending the human body parts with the use of a retractable manipulation gripper, c) by using a lift seat wheelchair with spring relief

Principles 4.3, 4.4 and 4.5, concerning structure ordering and adjustment, make it possible to see accessibility problems (e.g. in the camboose), which may also apply to standing cabinet arrangement (Fig. 7). Typical cabinet solutions are generally not accessible to wheelchair users (Fig. 7a). Similarly, access is also limited for an average-bodied (centile $\mathrm{C}_{50}$ ) standing person (Fig. 7b). Access to, for example, standing cabinets requires adopting uncomfortable body positions (e.g. for seniors) (Fig. 7c).

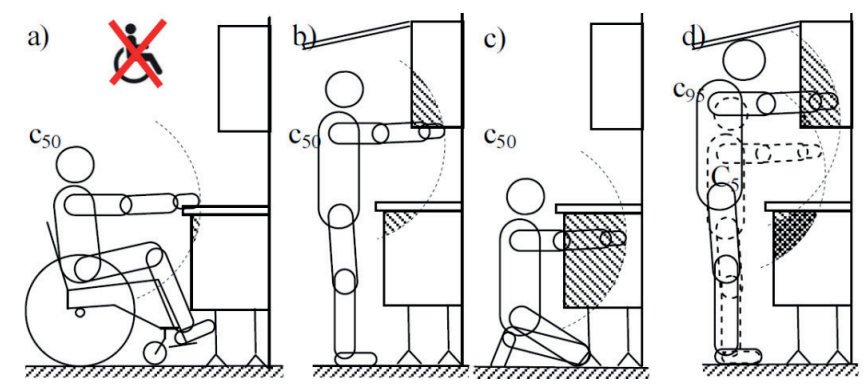

Fig. 7. Limited operator access to furniture as a result of restricted manipulation zone: $a$ ) in a seated position on a wheelchair, $b$ ) in a standing position for an average-bodied person (centile $C_{50}$ ), c) in a kneeling position, $d$ ) for persons in centiles $C_{5}$ and $C_{95}$

Changing the anthropometric dimensions of standing people (from centile $\mathrm{C}_{50}$ to $\mathrm{C}_{5}$ or $\mathrm{C}_{95}$ ) extends the access range to other cabinet interiors (Fig. 7d). Designing a furniture layout for wheelchair users and standing people is difficult due to colliding requirements. Similarly, the application of principles $4.3-4.5$ results in adapting the height of the tabletops to the anthropometric dimensions of the users (Fig.8). Several methods for raising the tabletop manually or electrically have been developed [15]. 

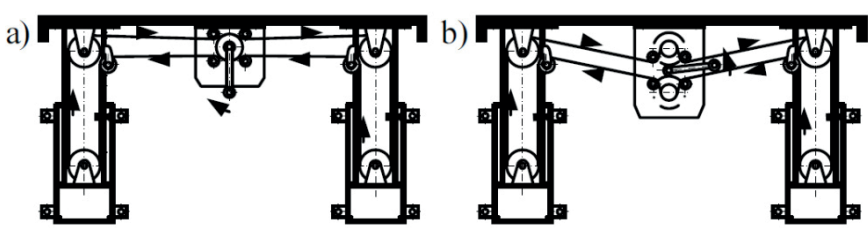

Fig. 8. Structural solutions for tabletop lifting mechanisms using: a) one pull rod, b) one pull rod and gear, c) two pull rods, d) three pull rods [15].

Cutlery and its handles should be adapted to anthropometry and disability degrees and comply with safety rules (no. 4.5). Making the grips thicker and longer boosts finger grip stability and enables a full grip (Fig. 9a). Restriction in the range of movement of hand joints requires an additional curve to limit the need for wrist movement (Fig. 9b) A handgrip reduces the need to flex the fingers in rheumatoid arthritis (Figure 9c). a)

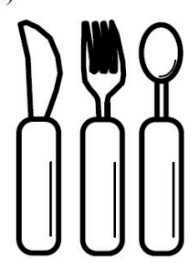

b)

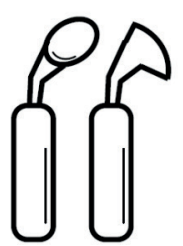

c)

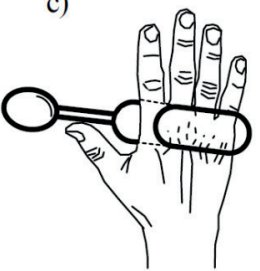

Fig. 9. Cutlery: a) a set with thickened and elongated handles for a firm grip, b) a spoon and knife for people with severe hand joint limitations, c) a spoon with a hand grip for people with manipulation and grip problems

Typical sailing activities are related to the handling of the rigging, among other things. When planning for this function, principles 2.1, 2.2 and 5 need to be examined. It is difficult for the physically disabled to pull the rope due to their low strength and problems with body stabilisation by a person sitting in a wheelchair and the very braked wheelchair with the drive wheels relieved (Fig. 10a) and adding weight to one limb by a standing person (Fig. 10b). Wheelchair stabilisation is improved by positioning it sideways to the rope pulling direction.

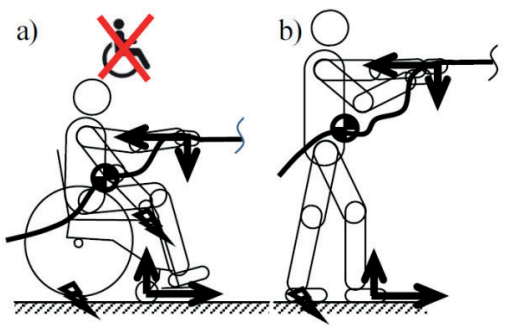

Fig. 10. Transmission of forces to the ground while working with the rope: a) by a person in a wheelchair, b) by a senior

Significant changes in the anthropometric (reach zones - see Fig. 6 and 7) and biomechanical (forces - see Fig. 10) dimensions of the disabled and seniors make it necessary to measure these individual features and include them in the design process. The measuring device (Fig. 11a-c) enables the study of individualised anthropometric and biomechanical features, whereas 3D graphic representation (Fig. 11d) enables data input to the design (Fig. 11c) [16].
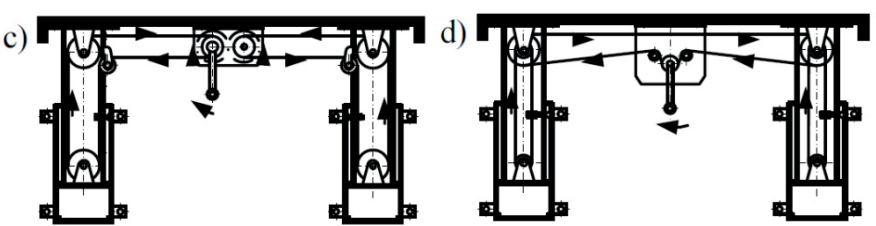

The safety-relevant rails (principles 1.4, 3.4 and 5.1) are also used by wheelchair users. Protection against falling overboard is provided by safety ropes fastened on the railing (Fig. 12) or sliding in the guides.

Yacht-specific conditions (e.g. variable weather conditions, deck inclination, significant changes in air temperature and humidity, wet deck) entail the need to develop a special yacht wheelchair. Modular wheelchair structures [17] with a common load-bearing and drive unit, allow a wide range of changes in wheelchair functionality, e.g. manual wheelchair transport, lifting the seat, verticalisation (Fig. 13). The visualisation shows a modular wheelchair with the seat providing improved comfort and safety to the disabled sailor on the yacht, through the use of a high backrest and lowered centre of gravity. It also provides for the possibility of transfer to the active wheelchair. It can be assumed that the design follows design principles 1, 2.4, 3.1 and 7.2.

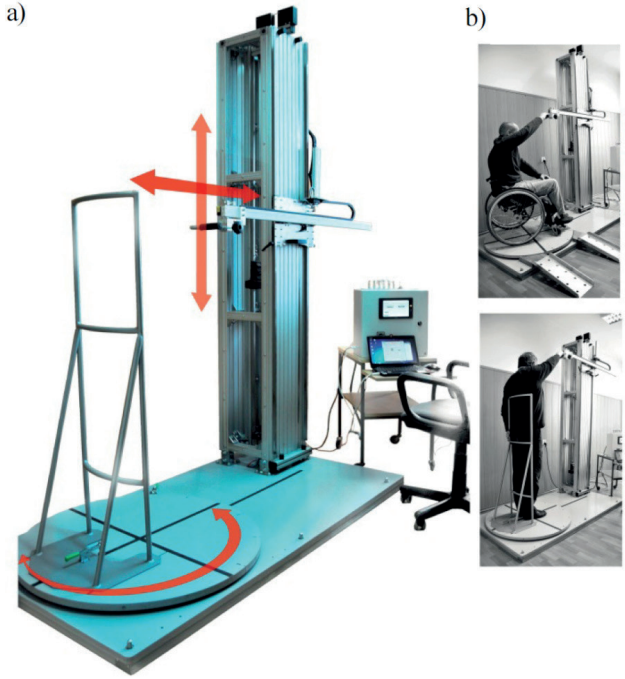

c)

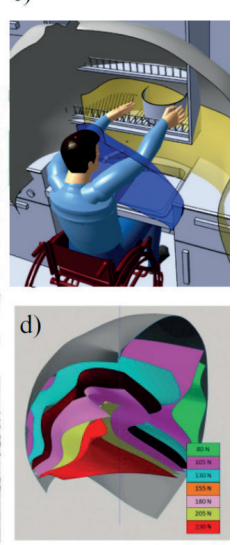

Fig.11. Device for measuring the manipulation space and upper limb forces of the disabled and seniors: a) measuring device in the PP Universal Design and Mobility Means laboratory, b) measurements, c) application of measurement results in kitchen accessibility studies, d) 3D graphic representation of forces and reach zones $($ see $[2,16])$
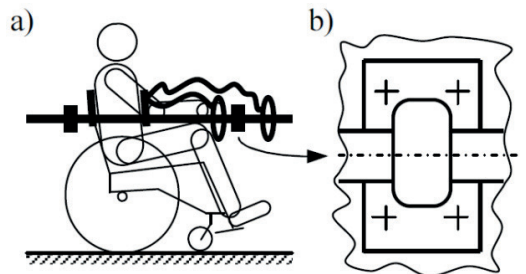

Fig. 12. Systems protecting from falling overboard with detachable ropes attached to handrail: a) detachable safety ropes, $b$ ) handrail attachment to the yacht 


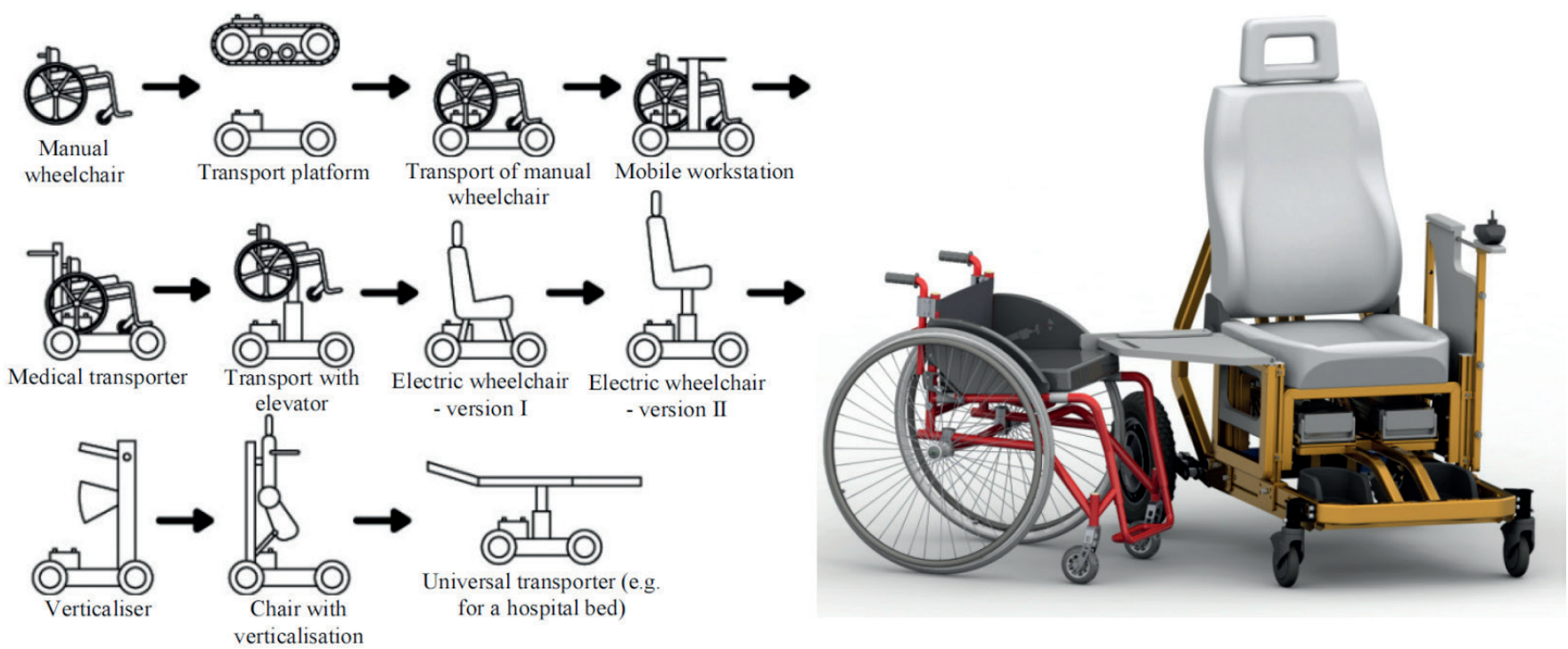

Fig. 13. A family of modular vehicles with a common load bearing-drive platform, together with the visualisation of one family representative: an electric wheelchair [2, 17].

The use of a Segway-based yacht wheelchair (Fig. 14) allows: wheelchair verticalisation at yacht angles of inclination up to 30 degrees (according to rule no. 2.3), overcoming significant height differences due to large wheels (according to rule no. 4.3), turning on the spot (according to rule no. 4.1, 7.1 and 7.5) and advanced control of driving parameters (according to rule no. 6.2).

a)

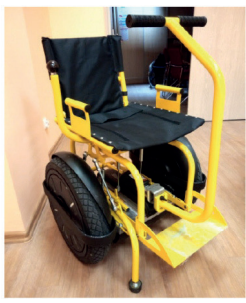

b)

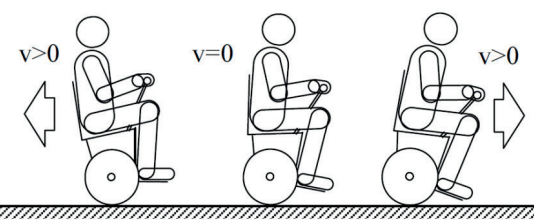

Fig. 14. Polish adaptation of the Segway-type wheelchair by Blumil to yachting for the disabled (a) and the way of moving on the wheelchair (b)

While planning the arrangement of usable areas inside the yacht, we analysed accessibility using mock-ups of yacht wheelchairs and 'turning wheels'. Fig. 15 shows a layout example for a section of the yacht superstructure with the following requirements (and rule 4.3) met: turning around in the kingston and kitchen, passage along the superstructure and transport by an inter-deck lift.

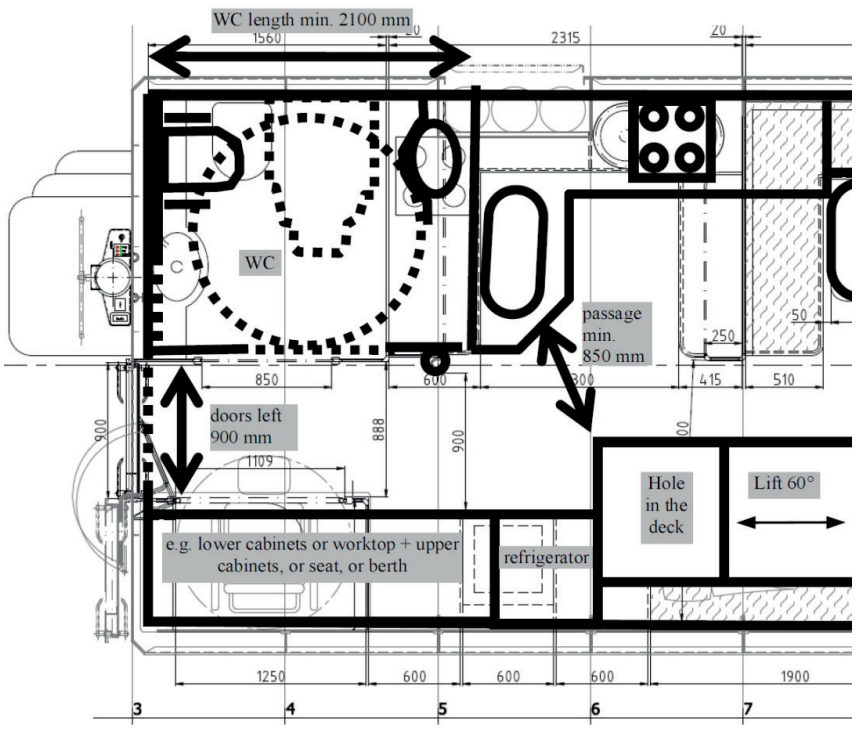

Fig. 15. Exemplary layout of a yacht superstructure fragment

\section{DISCUSSION}

This research discusses a peculiar sociotechnical system 'disabled sailors-sailing yachts'. The operation of such a system requires a socio-technical division of labour, in which human and technical function carriers interact. The applied universal design method, aimed at all yacht crew members, regardless of age, gender and disability during the performance of all the activities on the yacht, allowed for a deeper consideration of the required adaptations in the construction of an ocean sailing yacht. These relate to planning access, correct structure concept, changes in the proportions of the yacht's overall dimensions, deck and interior equipment to ensure transport, accessibility, and safety of the crew.

In the subject literature, a yacht for the disabled is the main subject of only a few publications, and the topics presented there are far from being exhaustive in designing such vessels. 
For example, the work of Cerveira et al. [18] considers, among other things, the limitations faced by yacht sailors related to disabilities. It presented several stages of yacht adaptation meeting the requirements of universal design. Major research directions included the elimination of the influence of the heeling angle, maintaining balance and mobility, yacht steering and sail handling, followed by adaptations for a particular user. The authors noted that simple solutions greatly boost yacht accessibility [18]. The paper by A. Banaszek [19] presents the application of several, typical structural solutions in a yacht for the disabled. The importance of this topic, from the perspective of emerging international legislation, was highlighted. It has been noted that, on modern yachts, depending on their physical limitations, the sailor may encounter problems when boarding or using outdoor and indoor spaces [20]. The research presented here aims to develop solutions to boost sailing yacht accessibility [20]. Theses from works [18-20] about the need to increase the accessibility of yachts remain valid. This is also confirmed by research by the EU Transport Committee, which judged accessibility of transport and tourism for people with disabilities as being fundamental [21]

The few previously cited publications [18-20] on yacht design are important and the knowledge contained therein still needs to be further developed. The development of specific principles for yacht engineering devices, supporting the work and leisure of persons with disabilities is another step in the process of standardising yacht design procedures. The presented case studies of adaptations of places where functions are performed by the disabled are intended to extend knowledge on essential adaptations to achieve yacht accessibility. These examples have been developed following the application of the above-mentioned principles.

The decision-making process in the design of ship power plants has been analysed [22]. This process has many features in common with general ship accessibility and safety. It means that accessibility, as a property of the designed object, can be shaped at the design stage.

The Empatia 60 FD yacht, currently under construction, is intended to provide access and safety, integration and training for sea sailing for the disabled community. However, the lack of sufficient examples of interior yacht designs for the disabled and seniors necessitates references to the literature on interior building design. Examples such as the design of an inclusive kitchen in a flat $[2,23,24,25]$ provide some insight into how a kitchen needs to be adapted on a yacht. Because such works do not take into account factors such as deck swaying, high humidity, wet deck and transfer of water to the deck (e.g. in the superstructure), these requirements must be formulated differently. As reported in [18], ensuring accessibility also means providing adaptations to the individual characteristics of the disabled (e.g. problems with reaching, lifting and manipulating heavy objects, large body mass or size). This results in the need to measure individual human strength and manipulation properties. The measurement device presented in this paper and the method of processing hand forces and ranges enable $4 \mathrm{D}$ information on the properties of a particular human to be used in computer systems $[2,16,24,26]$. This device can also be used for making measurements for people standing on sloping surfaces, such as a yacht.

Examples of new devices dedicated to yachting applications may include an ergonomic swivel seat used in Paralympic sailing boats [13], a rudder for the disabled [12] or lifted tabletops [15], a specially designed two-wheel self-balancing Segway-type yacht wheelchair or a seat module built on a common product platform [17].

On a yacht, people with motor disabilities require special consideration and equipment with technical means, i.e. wheelchairs. Again, the literature basically lacks any discussion on such technical means used on yachts. Any borrowing of wheelchair structural solutions, used materials, ensuring safety, proper selection etc. should start from the analysis of wheelchairs intended for land use, e.g. active wheelchairs $[11,27,28]$.

\section{CONCLUSIONS}

The following conclusions are drawn from the research:

1. The paper discusses a new and difficult issue of yacht design for disabled sailors. There are no known solutions to this problem in the world. Difficulties arise from the need for combining various alternative technical solutions in the same equipment for different possible disabilities (e.g. rudder, compass, helmsman's seat).

2. Designing an ocean yacht for disabled users requires an interdisciplinary approach. Apart from professional yacht designers, specialists in ergonomics, rehabilitation and disabled persons with sailing experience need to participate in this process.

3. Universal design principles cannot be fully transferred from land applications to yacht design, due to specific features of the yacht environment and its behaviour e.g. in adverse weather conditions.

4. The design principles given in this paper constitute a guide to obtaining correct solutions for the yacht and its equipment. It is not the yacht itself, as a technical measure, that poses design problems but a yacht with disabled sailors changing from voyage to voyage. Each disability requires support for a different activity.

5. Case studies of new concepts develop the design principles. Most examples of support for work and leisure activities concerned wheelchair users. These people need special assistance as difficulties in moving around the yacht, steering, handling can make the yacht inaccessible.

This paper presents partial results of a European project implemented by the National Centre for Research and Development (NCBR) under the Intelligent Development Operational Programme 2014-2020. Project designation and title: POIR.04.01.04-00-0122/17-00 "Design and construction of a prototype ocean schooner yacht for people with disabilities". 


\section{LITERATURE}

1. Jubilee Sailing Trust, "Jubilee Sailing Trust Annual Report for the year ended 31st March 2019," Jubilee Sailing Trust, Registered Charity \#277810, 2019. [Online]. Available: https://jst.org.uk/wp-content/uploads/2020/02/JST-FY19Annual-Report-FINAL-VERSION.pdf. [Accessed: July 30, 2019].

2. B. Branowski, Ed., Projektowanie dla seniorów i osób $z$ niepełnosprawnościami - badania, analizy, oceny, konstrukcje / Designing for seniors and people with disabilities - research, analyzes, assessments, constructions, Poznań, Wydział Maszyn Roboczych i Transportu Politechniki Poznańskiej, 2015.

3. M.Zabłocki, Aspekty systemowe i procesowe w projektowaniu technicznym dla osób z niepetnosprawnościami / System and process aspects in technical design for people with disabilities, Rozprawy nr 495. Poznań: Wyd. Politechniki Poznańskiej, 2013.

4. A. Karczewski and J. Kozak, "Variant designing in the preliminary small ship design process", Polish Marit. Res., vol. 24, no. 2, 2017, doi: 10.1515/pomr-2017-0052.

5. M. Pawłusik, R. Szłapczyński, and A. Karczewski, "Optimising Rig Design for Sailing Yachts with Evolutionary Multi-Objective Algorithm", Polish Marit. Res., vol. 27, no. 4, 2020, doi: 10.2478/pomr-2020-0064.

6. T. Niksa-Rynkiewicz, M. Landowski, and P. Szalewski, "Application of apriori algorithm in the lamination process in yacht production", Polish Marit. Res., vol. 27, no. 3, 2020, doi: 10.2478/pomr-2020-0047.

7. G. Ropohl, Allgemeine Technologie. Eine Systemtheorie der Technik, 2. Aufl. München/Wien: Hanser, 1999.

8. M. Gawrysiak, Analiza systemowa urzadzenia mechatronicznego/ Systemic analysis of a mechatronic device, Białystok: Wyd. Politechniki Białostoskiej, 2003.

9. J. Dietrych, System i konstrukcja / System and structure, Warszawa: WNT, 1978.

10. G. Pahl, W. Beitz, J. Feldhusen, and K. H. Grote, Konstruktionslehre, Berlin: Springer Verlag, 2007.

11. B. Branowski, M. Zabłocki, and M. Sydor, "The material indices method in the sustainable engineering design process: A review", Sustainability, vol. 11, no. 19, 2019 doi: 10.3390/su11195465.

12. P. Kurczewski, D. Torzyński, and M. Zabłocki, Stanowisko sterowe dla osób z niepełnosprawnościami na wózkach inwalidzkich/ Steering stand for wheelchair users with disabilities, P.433176.

13. M. Collotta, and L. Solazzi, "Design and realisation of swivellings paralympic racing boat", Journal of Accessibility and Design for All, vol.7 no. 2, 2017.

14. J. C. Linsley, "Yacht Obsession - Platform Lifts and Stairway Chairlifts", Elevator World, Jan. 1, 2020.

15. B. Branowski, P. Kurczewski, P. Pohl, and D. Torzyński, System for raising the workplace top, in particular for disabled persons, PL 230607.

16. B. Branowski, J. Gabryelski, S. Głowala, P. Pohl, M. Sydor, and Zabłocki M., Device for measuring the human manipulation space range in scope of forces and reaching limits, method for making measurements of the human manipulation space range in scope of the reaching limits and method for making measurements of the human manipulation space range in scope of forces, PL 226411.

17. B. Wieczorek, M. Zabłocki, B. Branowski, and S. Głowala, Transport or rehabilitation vehicle for persons with motor disability, PL 228166.

18. F. Cerveira, N. Fonseca, and L. Sutherland, "Considering disabled people in sailing yacht design", Maritime Engineering and Technology - Proceedings of 1st International Conference on Maritime Technology and Engineering, MARTECH 2011, (2012), doi: 10.1201/b12726-10.

19. A. Banaszek, „Technika przystosowania jachtu dla potrzeb osób niepełnosprawnych/ Technique of adapting a yacht for the disabled", Autobusy, vol 12, 2016.

20. P. Ferrari, A new approach for an inclusive yacht design. Advances in Intelligent Systems and Computing, 954, 2020, doi: 10.1007/978-3-030-20444-0_7.

21. Policy Department for Structural and Cohesion Policies Directorate General for Internal Policies of the Union, "Research for TRAN Committee - Transport and tourism for persons with disabilities and persons with reduced mobility", Policy Department for Structural and Cohesion Policies Directorate General for Internal Policies of the Union, PE 617.465, 2018. [Online]. Available: https://www. europarl.europa.eu/RegData/etudes/STUD/2018/617465/ IPOL_STU(2018)617465_EN.pdf [Accessed: July 15, 2021].

22. A. Podsiadlo and W. Tarelko, "Modelling and developing a decision-making process of hazard zone identification in ship power plants", Int. J. Press. Vessel. Pip., 2006, doi: 10.1016/j.ijpvp.2006.02.017.

23. A. Bonenberg, B. Branowski, P. Kurczewski, A. Lewandowska, M. Sydor, D. Torzyński, M. and Zabłocki, 
"Designing for human use: Examples of kitchen interiors for persons with disability and elderly people", Human Factors and Ergonomics In anufacturing, vol 29 nr. 2, 2019, doi: $10.1002 / \mathrm{hfm} .20772$.

24. B. Branowski, P. Pohl, M. Rychlik, and M. Zabłocki, "Integral model of the area of reaches and forces of a disabled person with dysfunction of lower limbs as a tool in virtual assessment of manipulation possibilities in selected work environments", Lecture Notes in Computer Science (including subseries Lecture Notes in Artificial Intelligence and Lecture Notes in Bioinformatics), 2011, 6766 LNCS(PART 2), doi: 10.1007/978-3-642-21663-3_2.

25. S. Goldsmith, Universal design, A Manual of Practical Guidance for Architects, Oxford: Architectal Press, 2000.

26. B. Branowski, L. Pacholski, M. Rychlik, M. Zabłocki, and P. Pohl, "Studies on a new concept of 3D data integration about reaches and forces of a disabled person on a wheelchair (CAD methods in car and market ergonomics)", Human Factors and Ergonomics In Manufacturing, vol. 23, no. 4, 2013, doi: 10.1002/hfm.20314.

27. M. Sydor, and M. Zabłocki, "Wybrane problemy doboru i konfiguracji wózka inwalidzkiego z napędem ręcznym / Selected problems in chosing and configuring a manualdrive wheelchair", Fizjoterapia Polska, vol 2, no. 4, 2006.

28. M. Sydor, A. Krauss, and H. Krauss, "Risk analysis for operation of active wheelchairs in non-urban settings". Annals of Agricultural and Environmental Medicine, vol 24, no. 3, 2017, doi: 10.5604/12321966.1235166.

\section{CONTACT WITH THE AUTHORS}

\section{Bogdan Branowski}

e-mail:bogdan.branowski@put.poznan.pl

Politechnika Poznańska,

Piotrowo 3, 60-965 Poznań,

Poland

\section{Marek Zabłocki}

e-mail:marek.zablocki@put.poznan.pl

Politechnika Poznańska,

Piotrowo 3, 60-965 Poznań,

$$
\text { POLAND }
$$

\section{Przemysław Kurczewski}

e-mail: przemyslaw.kurczewski@put.poznan.pl

Politechnika Poznańska,

Piotrowo 3, 60-965 Poznań,

Poland

\section{Andrzej Walczak}

e-mail:andrzej.walczak@doctorate.put.poznan.pl

Politechnika Poznańska,

Piotrowo 3, 60-965 Poznań,

\section{Poland}

